eCAM 2006;3(1)1-2

doi:10.1093/ecam/nek019

\title{
Editorial
}

\section{Complementary and Alternative Medicine: Challenge to eCAM}

\author{
Edwin L. Cooper \\ Laboratory of Comparative Neuroimmunology, Department of Neurobiology, David Geffen School of \\ Medicine at UCLA, University of California at Los Angeles, Los Angeles, CA 90095-1763, USA
}

Our new journal eCAM, Evidenced-based Complementary and Alternative Medicine has just celebrated a major milestone since its birth in 2004. Conceived and incubated in Kanazawa, Japan and born at UCLA, Los Angeles with assistance from Oxford University Press. With this editorial, we enter our third volume; $e C A M$ is 2 years old, i.e. two volumes that are hard copy. Electronic submission and peer reviewing hasten publication by advance access before the appearance of a hard copy issue. Although these points may be old news to some, our international travels have taught us that many of our potential authors and readers are unaware of these publication policies and mechanisms. Moreover, it seems not universally understood that because we are young we are still waiting for an impact factor. Happily and with relief, we are on the positive path, having been monitored by PubMed since volume 1 and recently listed in ISI retroactive to volume 1 . To follow the infant analogy, rather than being the usual assertive 2-year-old whose response is the emphatic 'no', eCAM adopted the more broad yet cautious view and published what we considered the best of available papers that were scientific and evidence based; among those, some were distinctly clinical.

An equally positive and early direction toward scientific rigor is due to a preponderance of editorial board members who are biologists of various specializations, e.g. immunologists, neuroscientists, endocrinologists along with others who are considered more bona fide classical members of the community of complementary and alternative care givers. Yet, with the turn of the New Year and the appearance of volume 3, we are still grappling with a dearth of classical CAM papers that are solidly evidenced based. From conception, I have pondered a solution to this rather unfocused

For reprints and all correspondence: Edwin L. Cooper, Distinguished Professor, Laboratory of Comparative Neuroimmunology, Department of Neurobiology, David Geffen School of Medicine at UCLA, University of California at Los Angeles, Los Angeles, CA 90095-1763, USA. Tel: +1-310825-9567; Fax: +1-310-825-2224; E-mail: ecam@mednet.ucla.edu mélange that would not compromise our mission to publish strong papers that are evidence based. I initiated this quest in my very first editorial (1) and in several othersemphasizing the need for rigor, strong science. Like all growing creatures, we learn, we advance, we learn more and we advance further ad infinitum. Of course the level and extent of our growth in any direction will depend upon our contacts, interested readers, potential authors and a cooperative editorial board and many diligent referees who unselfishly contribute their valuable time to the review process in order to publish high quality papers.

We set about in several directions across the wide field of complementary and alternative medicine. One of our most enthusiastic forays opened up the untapped resource of natural products, especially those derived from animals (e.g. sponges, mollusks and earthworms). This area gained such considerable attention that we have adopted the term bioprospecting. This area may seem far from the clinical work implied by the title of our journal, yet as a biologist I see this as laying the foundation for new and exciting products that will eventually make their way into the clinical arena. At the same time, though, we have kept our commitment to the orientation of medicine and have included some true clinical papers that are theoretical (2-5), practical and even some that are based upon readily applicable and easily recognized animal models $(6,7)$. Now our journal deems it essential to embark on a more rigorous and concerted tact broadening our 2 year attempts to recruit, review and publish high quality papers that are clinical. This is what was urged in the last editorial of 2005 (8).

Will our strategy for volume 3 and 2006 be different from that which generated clinical papers for volumes 1 and 2? How shall we define acceptable papers that are high quality? We focused on this concern most recently while in Daegu, Korea at the International Congress of Oriental Medicine in October 2005-after administrative and editorial meetings in Tokyo and later lectures and Editorial Board meeting

(C) The Author (2006). Published by Oxford University Press. All rights reserved.

The online version of this article has been published under an open access model. Users are entitled to use, reproduce, disseminate, or display the open access version of this article for non-commercial purposes provided that: the original authorship is properly and fully attributed; the Journal and Oxford University Press are attributed as the original place of publication with the correct citation details given; if an article is subsequently reproduced or disseminated not in its entirety but only in part or as a derivative work this must be clearly indicated. For commercial re-use, please contact journals.permissions@oxfordjournals.org 
in Beijing. Our International Administrator, Patty Willis, called attention in a report sent to our Editorial Board shortly thereafter in early November. In this note she mentioned: 'Our ground-breaking meeting in Korea was a time to reflect on what we have accomplished as well as look to the years ahead'. As already mentioned, there has always been a concern for how to broaden our search to find a way to open $e C A M$ to more clinical work. During our gathering in Korea with Korean and Japanese Editorial Board members, we all agreed that this was an important new direction for the future. We decided to actively encourage the submission of clinical work in four different forms: (i) brief case reports; (ii) developed case reports with detailed, illustrative documentation; (iii) case reports expanded into hypotheses; and (iv) clinical studies that have as strong an evidence base as possible are absolutely essential. As a clinician, you will need to choose which of these four categories best suits the data you deem worthy to present.

As clinicians dealing each day with patients, your first concern is naturally 'if' something works, not 'why' something works. As I expressed in my last editorial, we are asking you to be brave, to take the data as far as you can, to ask difficult questions and even develop hypotheses (Option iii). As has always been true in the world of knowledge, there are clinicians and scientists at this very moment in other parts of the world who are grappling with the same questions. Perhaps your experience contains that vital piece of a puzzle needed halfway across the world or in a hospital across town.

Just as paintings that show as much from the brush strokes as from what the artist has left blank, be clear in your writing about what you feel to be missing, about the questions that remain unanswered. Once you submit your paper, it will go through a rigorous review before publication. Do not be discouraged by this process, for the duty of the referees is to guide you even farther along a more rigorous path. If you are not in accord with their comments, expand on the reasons why you disagree. Your paper will be strengthened by the inclusion of their concerns and your rebuttal.

In 1998, the National Center for Complementary and Alternative Medicine (NCCAM) was established by the US Congress at the National Institutes of Health (Bethesda, MD, USA) to rigorously investigate CAM modalities in order to determine which are beneficial and worthy of further consideration for mainstream practice. Introduced in my other editorials because of its clear delineation of what comprises the evidence base of clinical work, the CAM pyramid of Goldrosen and Strauss (9) gives order to the array of clinical articles. Beginning at the base with the least desirable of approaches such as anecdotes and case studies it reaches up to the sky with large-scale Phase III trials.

How will we implement this new thrust? We are at work now with our offices in Tokyo and Oxford to define $e C A M$ 's rules for publishing clinical papers in the four categories described earlier. The rules can be quite varied from numbers of words, figures, etc. Infusing the concept of basic biology, we could move from a brief observation to a full-fledged study. Let us see what happens in 2006-our New Year's challenge. Let us strive for more relevant and high quality papers that are clearly clinical. To succeed, we will need the strong support of our editorial board. Clearly $e C A M$ is our journal and to achieve this singular and important goal requires the active collaboration of the editorial board to help us attract the most exciting clinical work to $e C A M$ from their areas of influence all over the world.

\section{References}

1. Cooper EL. Complementary and alternative medicine, when rigorous, can be science. Evid Based Complement Alternat Med 2004;1:1-5.

2. Olalde Rangel JA. The systemic medicine theory of living systems and relevance to CAM: Part I: The theory. Evid Based Complement Alternat Med 2005;2:13-8.

3. Olalde Rangel JA. The systemic medicine theory of living systems and relevance to CAM: The theory (Part II). Evid Based Complement Alternat Med 2005;2:129-37.

4. Olalde Rangel JA. The systemic theory of living systems and relevance to CAM: the theory (Part III). Evid Based Complement Alternat Med 2005;2:267-75.

5. Olalde Rangel JA, Magarici M, Amendola F, del Castillo O. The systemic theory of living systems. Part IV: Systemic medicine-The Praxis. Evid Based Complement Alternat Med 2005;2:429-39.

6. Kiyohara H, Matusumoto T, Yamada H. Combination effects of herbs in a multi-herbal formula: expression of Juzen-taiho-to's immuno-modulatory activity on the intestinal immune system. Evid Based Complement Alternat Med 2004;1:83-91.

7. Wang XQ, Takahashi T, Zhu SJ, Moriya J, Saegusa S, Yamakawa J, et al. Effect of Hochu-ekki-to (TJ-41), a Japanese herbal medicine, on daily activity in a Murine Model of chronic fatigue syndrome. Evid Based Complement Alternat Med 2004;1:203-6.

8. Cooper EL. eCAM is waiting for eCAM. Evid Based Complement Alternat Med 2005;2:427-8.

9. Goldrosen MH, Strauss SE. Complementary and alternative medicine: assessing the evidence for immunological benefits. Nat Rev Immunol 2004;4:912-21. 


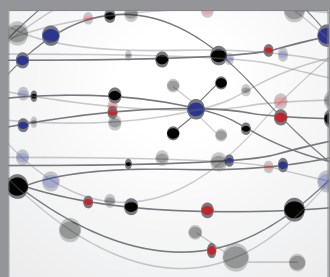

The Scientific World Journal
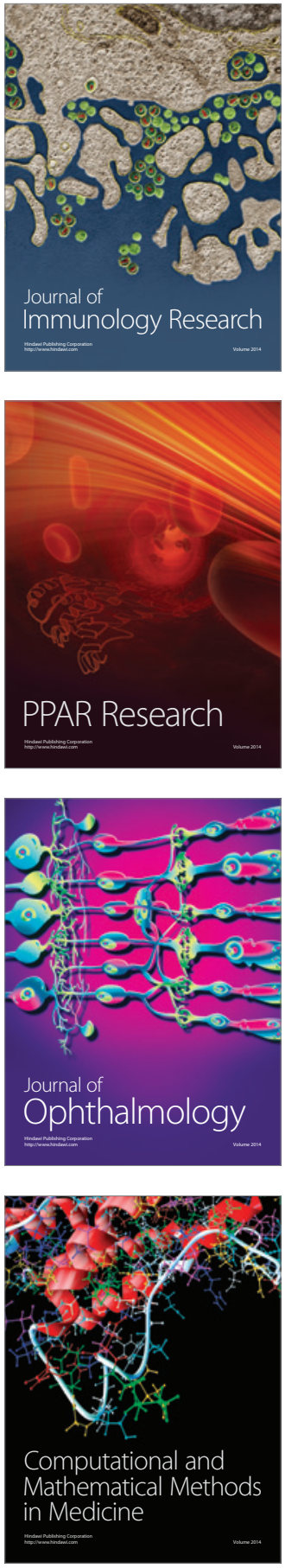

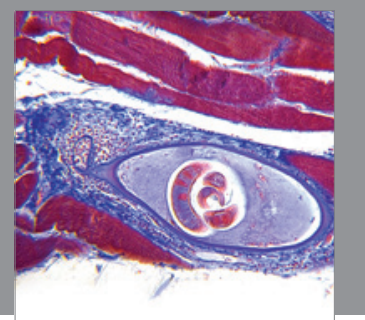

Gastroenterology

Research and Practice
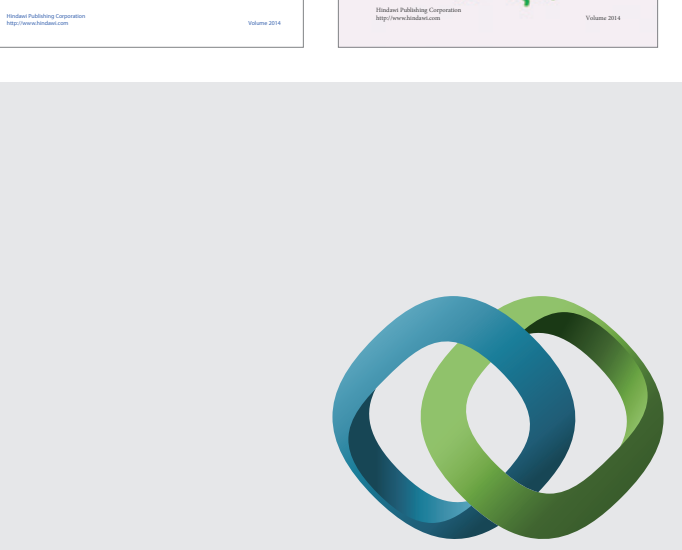

\section{Hindawi}

Submit your manuscripts at

http://www.hindawi.com
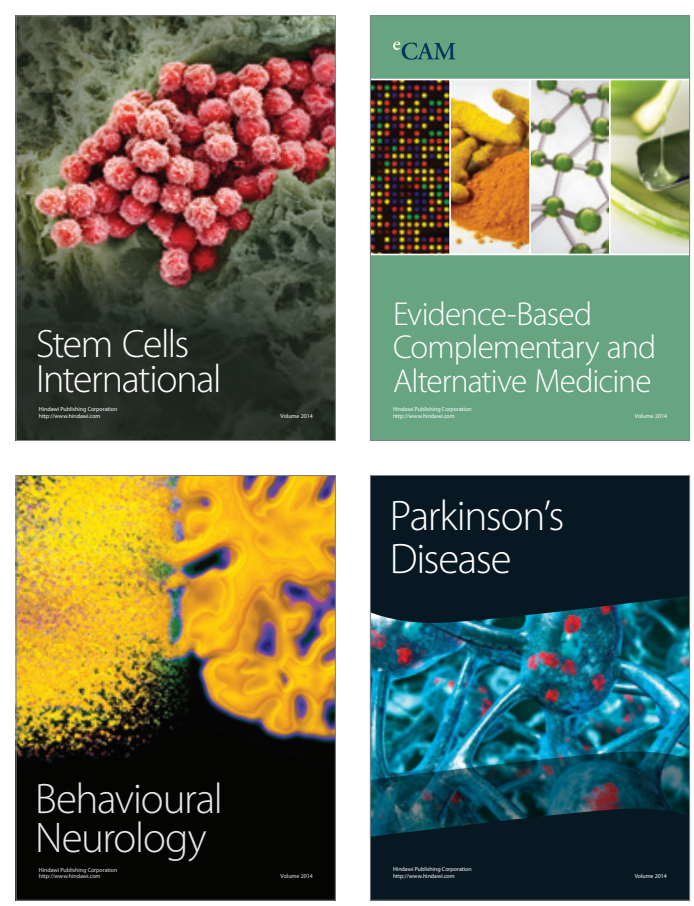

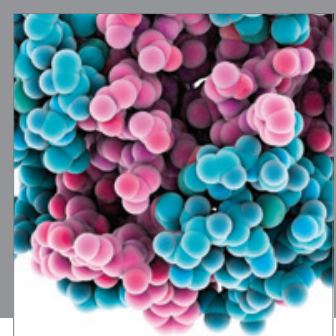

Journal of
Diabetes Research

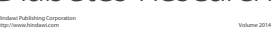

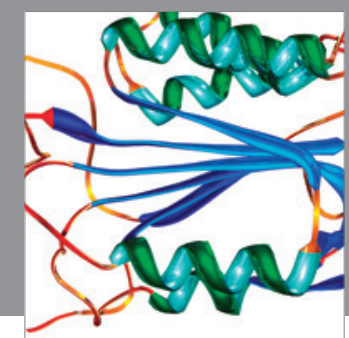

Disease Markers
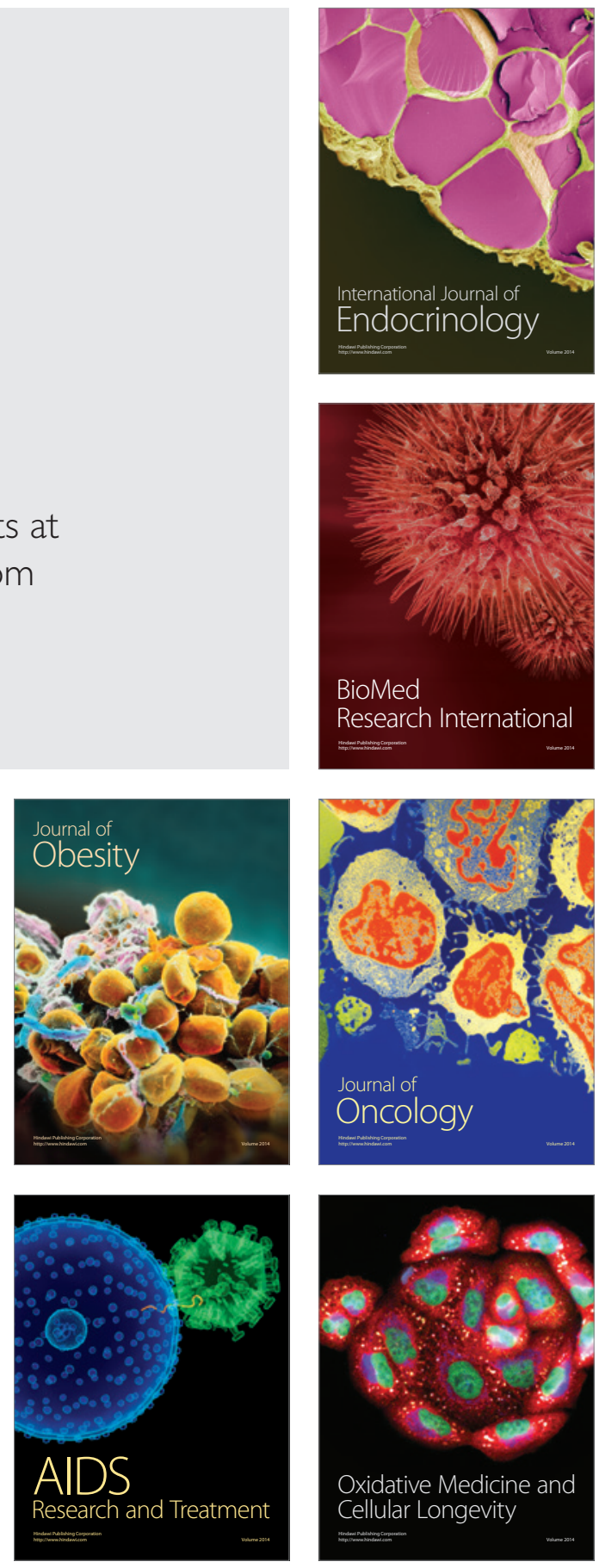